\title{
Revitalização de Centros Urbanos o Novo Paradigma de Desenvolvimento e seu Modelo Urbanístico
}

\section{Vicente Del Rio}

São discutidos os modelos urbanísticos e as imagens ideais gerados pelos quatro principais paradigmas de desenvolvimento perseguidos desde o final do século passado. Seus rebatimentos nas areas centrass são a nossa preocupação principal e contesta-se sua aplicabilidade direta enquanto baseados em modelos idealizados e/ou contextos não-específicos. O paradigma da revitalização mostra-se viável por sua flexibilidade e pluralidade; destacam-se alguns de seus aspectos positivos, mas aponta-se o perigo na importação de modelos e imagens. \footnotetext{
discuss the urban models and ideal images generated within the four major development paradigms that society followed since the late XIX century. Our primary concern is their implementation in the inner city: we doubt that they might be directly applicable if based whether on idealized models or on nonspecific contexts. The paradigm of revitalization proves itself viable for its flexibility and pluratity However, while we show some of its positive aspects we also point out to some of the dangers in importing models and images.
}

Arigo elaborado com base na Tese de Doulorado "Desenho urbano e revitalização na área portuária do Rio de Janeiro a contribuiçāo do estudo da percepção ambiental". apresentada em fulho de 19.91

Orientador: Prof. Dr. Lauro Bastos Birkholz. 
Neste trabalho discutiremos brevemente os principais paradigmas e modelos que têm norteado as intervençōes públicas nos centros urbanos a fim de discutir mais detalhadamente o modelo da revitalização urbana, com atenção particular para o contexto do Rio de Janeiro. Como conjuntos ideológicos modelares e, portanto, inalcançáveis, os paradigmas condicionam todas as açōes de uma sociedade em sua busca por perfeição, o que inclui modelos urbanísticos e imagens ideais para as áreas urbanas centrais. Esses paradigmas e seus modelos surgiram a partir de pensamentos originados em outros paises, cujos contextos políticos, econômicos e sócioculturais são bastante diferentes dos brasileiros. Chamaremos a atenção para os perigos inerentes da adoçāo irrestrita de modelos e imagens ideais importados, pois a realidade e a sociedade brasileira diferem, muitas vezes fundamentalmente, em suas necessidades sócioculturais e nas características do seu desenvolvimento urbano. Numa época de crise global em que se busca um ideal de revitalizaçāo para as áreas centrais degradadas e subutilizadas, cabe ainda mais essa preocupaçāo por conta do seu potencial em viabilizar mudanças nas esferas cultural. social, política e econômica das cidades.

A importância das áreas centrais esta profundamente ligada a suas lógicas históricas e sócioespaciais e é por isto que elas se destacam nas nossas percepçōes e vivências de quaisquer cidades. (Castells. 1971) já observou que as principais funções do centro urbano em nossa sociedade sempre gravitam em torno a duas noções: a integradora (nivel funcional e social) e a simbólica (nivel imagético e lúdıco). O lugar central de uma cidade assume papéis de centro inovador, de intercâmbios e simbólico; caracteristicas presentes nas expectativas de qualquer pessoa relativas a um "centro de cidade" O centro se realiza, portanto, nas imagens públicas da maioria das cidades, embora especificidades geográficas e de evolução de algumas metrópoles haja gerado exceçōes. Este é o caso do Rio de Janeiro, uma vez que seus atributos nāo foram suficientemente fortes para competir com as praias e a zona sul no repertório imagético coletivo, relativo às qualidades da cidade e de suas áreas mais representativas. Fato, entretanto, que tende a se modificar, não só pelo potencial de seu estoque histórico-arquitetônico e de imóveis subutilizados. como pelas crescentes iniciatıvas públicas e privadas, principalmente lıgadas ao Projeto Corredor Cultural e à promoção comercial e cultural.

Evidentemente, os modelos e imagens ideais perseguidos por intervenções que objetivam a revitalização de áreas centrais deverão coincidir com os repertórios de imagens e as expectativas de sua populaçāo usuária - desde moradores a investidores ${ }^{1}$ (Del Rio, 1991). Sua operacionalizaçāo consciente, através de políticas, programas e projetos urbanísticos, será sempre indispensável para que as ações públicas possam suscitar transformações e impactos verdadeiramente positivos, seja no desenvolvimento econômico e sóciocultural da área e de suas comunidades, residente e usuária, seja no da cidade como um todo ${ }^{2}$

(1) Esse for o tema principal de nossa pesquisa para tese de doutorado. In DEL RIC 1.991

(2) Para exemplos nesse sentıdo, veja-se DEL RIO 1990 e 1991 Exemplo brasıleiro bem susce. dido neste aspecio tem sido a cidade de Curitiba e a atuaçáo de Jaıme Lerner Suas realızaçoes e programas urbanístıcos sáo ampla e agressiva mente divulgados a nivess nacional e internacio nal, Curitıba é atualmente considerada exemplar como uma "cıdade do Tercerro Mundo que parece ser no primeiro" e como capılal mundial da ecolo gia Veja-se DEL RIO 1992 e GARCIA 1993
Pos - R Prog Pós-Grad Arquit. Urb FAUUSP Sáo Paulo n 4 p $5.3-64$ dez 1993

\section{Paradigmas e Modelos para Intervenções em Centros Urbanos}

O centro urbano é local privilegiado das politicas públicas e programas de intervenção urbanística: como símbolo máximo de detenção de poder, ele sempre se revela extremamente exposto aos sucessivos paradigmas imagéti$\cos$ das classes dominantes. Historicamente, isto se verifica a partir do momento de definição dos rebatimentos espaciais da sociedade capitalista e sua 
lógica. Com a revolução burguesa, a cidade viria tornar-se assunto capitalista: geração de renda do solo, clarificaçāo dos niveis de apropriaçāo e consumo do espaço, organização e hierarquizaçāo deste espaço. A consolidaçāo da burguesia no poder das cidades levou ao fortalecimento das funçōes econômicas urbanas e tornou cada vez mais transparente que à cada prática social corresponde uma organização físico-espacial (Castex et al., 1977).

O estudo da evolução das intervenções urbanísticas nos centros urbanos permite diferenciá-las por períodos que se caracterizam pela natureza de seus objetivos e. conseqüentemente, pelos resultados obtidos (Boucher, 1979; Benevolo, 1985; Portas, 1985: Frieden \& Sagalyn. 1989). Sāo objetivos que partem de ideologias e paradigmas de desenvolvimento urbano, inatingiveis por definição mas que passam a moldar a propria realidade. Esses paradigmas nos permitem identificar quatro modelos urbanísticos que foram clara e sistematicamente aplicados na maioria das grandes metrópoles mundiais. Os impactos foram variados e não cabe aqui seu detalhamento profundo. basta observar que a maioria de seus rebatimentos ainda são facilmente identificáveis nos tecidos dessas cidades. Veremos. inclusive. que alguns ainda são modelares até hoje. É interessante fazer notar que, enquanto os três primeiros modelos e suas imagens ideais possuem raizes européias, principalmente francesas, a inspiração do modelo atual é nitidamente norte-americana.

\section{O modelo do embelezamento e do saneamento}

Este primeiro paradigma é verificavel a partır do modelo das intervenções urbanas do Barão Haussmann, prefeito de Paris sob Napoleão III, de 1853 a 1870. São marcos da alteração das práticas de Estado para com as áreas centrais que definiram uma ruptura sócioespacial e a transformação de lógicas urbanas "pluralistas" para lógicas capitalistas (Choay, 1969; Castex et al., 1977; Chiavari, 1985). O solo urbano passaria a ser visto como uma valiosa mercadoria e as novas intervençōes iriam contrariar as estruturas existentes, impondo novas lógicas funcionais, sociais e econômicas. Dominaria a ideologia que, em última instância, a justificativa única para a existência das cidades é função das vantagens que elas oferecem aos processos de produção e consumo. Uma noção reducionista de vida que passaria a dominar cada vez mais as sociedades ocidentais, pelo menos até o fim dos anos 70 .

O momento de imposição deste novo paradigma e seus modelos urbanístıcos ideais no Brasil é claro. A partir do início do séc. XX, o Rio de Janeiro foi a primeira metrópole brasileira, seguida por São Paulo, onde se daria uma progressiva inserção de práticas capitalistas de reprodução e consumo nas lógicas sócıespaciais e seu rebatimento na hierarquização do territorio (Abreu, 1987; Chiavari, 1985). Nestes casos os centros se revelavam como lugares privilegiados para intervençōes, sempre no sentido de viabilizar o avanço do capital imobiliário e industrial. No Rio, então Capital Federal, o presidente Rodrigues Alves incumbia o prefeito Pereira Passos de promover programas e projetos de renovaçāo, na busca por uma nova imagem para o país, que ajudasse a atrair investimentos estrangeiros e a internacionalizar nossa economia. (Benchimol, 1985) chegou a afirmar que, neste momento, o Estado pareceu pela primeira vez como "interventor racional" da globalidade das ações capitalistas sobre o espaço urbano.

O centro urbano carioca, portanto, passaria a ser local privilegiado das intervençōes governamentais e território de implantação do modelo viabilizador das novas práticas econômicas e urbanisticas. As imagens perseguidas buscavam torná-lo atrativo porque belo, moderno e funcional: conduziu-se fartas demoli- 
ções de edificações insalubres assim como inúmeras outras obras de "embelezamento" Implantava-se desde programas de saúde pública, comandados por Oswaldo Cruz, até inúmeras obras públicas de porte. Os bairros da área portuária foram palco da famosa Revolta da Vacina e o tecido do centro foi rasgado pela construção da larga e elegante avenida Central, ladeada por prédios que nada iriam dever a seus pares europeus. Construíu-se um novo porto, áreas e armazéns de apoio, prontos para a importação e a exportação de um crescente mercado internacionalizado e competitivo.

\section{O modelo da cidade modernista}

A partir dos anos 20 e consubstanciando-se na Europa no período do pós-guerra, uma nova ruptura paradigmática incorporava conceitos e objetivos racional/ funcionalistas a açōes governamentais. Este paradigma de desenvolvimento modernista surgiu como resposta às condições herdadas da Revolução Indus. trial, as péssimas condições de vida urbana e moradia. O positivismo dominava a noção de desenvolvimento e as novas técnicas e o progresso industrial deveriam. ao mesmo tempo, viabilizar a maximizaçāo do capital investido e promover melhores condiçōes de moradia. A Arquitetura e o Urbanismo do movimento moderno adotariam uma visão futurista ingênua e otimista, que perseguia uma estética ideal numa sociedade de tipo "coletivismo democrático" (Blake. 1974).

Os congressos de Arquitetura Moderna, principalmente com a "Carta de Atenas" de 1933, e os escritos e obras de Le Corbusier foram os principais responsáveis pela expansão dos modelos e imagens do paradigma de desenvolvimento modernista (Frampton, 1981; Barnett, 1986). O modelo de casa como "máquina de morar" se uniria ao da cidade ideal e suas cinco funções assepticamente dispostas. Destacavam-se a Ville Radieuse e a Cité Contemporaine; soluções radicais, operações cirúrgicas como o melhor "remédio" à desordem morfológica e social, negação dos espaços e elementos tradicionais "confusos e obsoletos" e do "caótico tecido urbano" Buscava-se a "substituição pura e simples das estruturas físicas existentes como condiçāo apriorística da adaptação das cidades herdadas às necessidades da vida moderna" (Portas, 1985: 8).

A recuperação econômica e a reconstrução do pós-guerra possibilitou a institucionalização do Modernismo nas áreas centrais, logo ampliada com a expansão financeira e o desenvolvimentismo dos anos 60: fuga da classe média para os subúrbios; expansão das atividades administrativas, financeiras e de serviços; demolição de "áreas deterioradas" (leia-se modelos diferentes dos vigentes) e com "grupos marginais" (leia-se migrantes, minorias e pobres); lutas contra "deseconomias" de mercado (leia-se expansão de grupos monopolistas); e exacerbada importância para a engenharia viária e o transporte individual. Para Castells (1971: 270), "o mito da renovação urbana é um dos pilares da ideologia tecnocrática de reforma social através de soluçōes físicas"

Nos paises do Primeiro Mundo, a renovaçāo urbana foi institucionalizada como política oficial de intervenção nas áreas centrais. Inumeras atrocidades foram cometidas em prol deste paradigma, tanto a nível social, contra as comunidades locais (em sua grande maioria politicamente marginalizadas), quanto fisico-arquitetônico, arrasando importantes estoques histórico-culturais. A chamada "decadência" social e econômica era a justificativa para grandes intervençōes (Castells, 1971; Frieden, Sagalyn. 1989). Foi neste contexto, por exemplo, que no início da década de 60 , surgiram projetos de renovação de áreas centrais históricas em cidades como Londres (Covent Market) e Paris 
(Les Halles), com a demolição de importante patrimônio cultural e arquitetônico e que atingiram grandes impactos econômicos.

No Rio de Janeiro esse paradigma, seus modelos e ideais de imagens, justificou, por exemplo, a demoliçāo do Morro de Santo Antônio nos anos 50, e inspirou o projeto modernista de Afonso Reidy para a nova esplanada; embora inacabado e bastante modificado, sua herança é clara ainda hoje. Depois, no início dos 60 os planos viários viriam a justificar demolições e projetos de renovação, como o da Cidade Nova que arrasou bairros imediatamente periféricos à área central; neste caso ainda se destacava um viés moralista ao se remover a maior área de baixo meretrício da cidade, a Zona do Mangue. Em seu lugar, o modelo modernista propunha o novo centro administrativo municipal e um conjunto de edifícios comerciais. Com a expansão do capital financeiro, industrial e imobiliário, e os consequèntes rebatimentos na produção e consumo do urbano, a renovaçāo urbana modernista caracterizaria o "bom administrador público" até o fim dos anos 70 , imprimindo marcas em todas as metrópoles mundiais.

Muito da lógica por detrás das operaçōes de renovação estava intimamente ligada à questão da percepção e do conflito de valores e expectativas. Para a classe dirigente e seus tecnocratas, as antigas estruturas não correspondiam a suas imagens de civilidade e modernidade, uma vez que eles eram incapazes de compreender sistemas de valores das populaçōes residentes - diferen. tes dos seus - ou eram insensíveis à séria questão político-ideológica em que estavam envolvidos. O conflito de percepção fundamental residia no simples fato de que o que era deteriorado para uns, nāo o era para outros; muitas vezes os tecnocratas sequer visitavam as áreas que se apressavam por categorizar. "A decadência estava nos olhos de quem olhava. (Frieden, Sagalyn, 1989).

Finalmente, a visāo romântica da tecnologia moderna, que originalmente se propunha a liberar o indivíduo das limitaçōes da tradiçāo, revelou-se especialmente adaptável à repetição burocrática inconsciente e aos sobrelucros do capitalismo (Barnett, 1986). A negação da cidade existente, a recusa em se considerar condições específicas de implantação, a autonomia relativa da forma sobre o social e psicológico, e o espaço visto em termos absolutos e eternos, são aspectos que demonstram a redução teórica dos modelos urbanos do paradigma modernista (Castex et al. 1977).

\section{O modelo da preservação histórica e do conservacionismo}

As críticas ao paradigma desenvolvimentista, seus modelos e políticas urbanas, conduziriam a um terceiro momento de ruptura. Nesse momento, a opinião pública já conseguia avaliar e posicionar-se em relação aos resultados concretos impostos pelo modernismo, além do que as crescentes atividades políticas de grupos comunitários passaram a influenciar nos conceitos de desenvolvimento e na noção de cidade ideal. Foi a "era" do conservacionismo nos países do Primeiro Mundo, quando tudo era motivo de preservação e a ação política. muitas vezes radical, garantia os tombamentos, áreas históricas. relatórios de impacto ambientai, controle de poluição. etc. Multiplicavam-se os rebatimentos deste paradigma nas políticas sobre os centros urbanos. 0 modelo urbanístico refletia a crescente onda de busca por identidades (nacionais e regionais), de fortalecimento de bases culturais e da crescente indústria de turismo, o que justificava a "sacralização" de lugares e edificaçōes pela sociedade (Appleyard, 1979). 
O modelo urbanístico assumido agora "congelava" as testemunhas históricas, via a arquitetura como monumento, os edifícios como museus e as obras de intervenção seguiam rasgos puristas e respeitosos de um passado que, às vezes, nem participava da memória coletiva dos usuários da cidade. As edificações antigas eram sacralizadas pelo simples fato de já existirem. Iniciandose por Itália, França e Inglaterra, todos os países europeus viveram intensamente este paradigma; em Varsóvia; a praça central chegou a ser reconstruida como réplica exata da original destruída pela guerra. O preservacionismo radical era uma reaçāo natural ao período anterior, em que as demolições e riscos ao meio ambiente eram exacerbados e irresponsáveis, em nome de um conceito de progresso bastante relativo.

Em nosso país, o poder público e o capital ainda estão aprendendo o valor e o respeito a estes ideais. Ainda não superamos plenamente este periodo e os grupos comunitários ainda buscam soluções radicais de preservaçāo. Embora a luta política geralmente indique este caminho como a única maneira de se atingir situaçōes ideais ou de compromisso, muitas vezes existe uma busca ingênua ou reacionária de imagens saudosistas, cujos rebatimentos sociais, culturais e econômicos também podem ser contestados.

\section{O modelo da revitalizaçāo urbana}

O paradigma de desenvolvimento, que tomou corpo nos anos 80 , formou-se a partir de uma série de crises (política, energética, ecológica, econômica) que passaram a expor a fragilidade da nossa sociedade. principalmente dos seus sistemas social e econômico e a forma com que se expressam nas grandes cidades (Tanghe et al., 1984). Estamos vivendo intensamente esse periodo de crises, que está sendo particularmente negativo para as economias e cidades do Terceiro Mundo. Na última década o desinvestimento passou a caracterizar as metrópoles, refletindo-se em suas várias esferas: qualidade dos serviços. conservação dos sistemas públicos, concentração da misérıa, relações humanas, aumento de criminalidade e insegurança geral. etc. Os economistas chamam os anos 80 de década perdida.

Este novo contexto, em conjunto com a ampliaçāo dos movimentos democráticos, fez com que a administração pública e o capital passassem a reconhecer a importância do patrimônio instalado, seja ele social ou físico e particularmente nas áreas centrais. O novo paradigma de desenvolvimento busca uma melhor utilização. ou melhor, reutilização do patrimônio existente: modelos que viabilizem o sistema econômico mas que. ao mesmo tempo. possibilitem utilizar potenciais instalados e atinjam melhores respostas sócioculturais. Neste sentido é que se popularizou o modelo da revitalização urbana. que promove objetivos de desenvolvimento urbano e ações integradas com o fim de possibilitar "nova vida" às áreas urbanas decadentes ou subutilizadas. As principais cidades da Europa, que sentiram a crise econômica em conjunto com sérias limitações territoriais e que contavam com importante patrimônio arquitetônico das áreas centrais, se dispuseram a reverter suas políticas de descentralizaçāo (Tanghe et al., 1984; Benevolo, 1985). O novo paradigma de desenvolvimento passaria a promover um modelo de revitalização que "toma como um dado econômico e cultural a estrutura e a forma da cidade ... como um dado social a trama de relações sociais e de atividades que (elas) ... suportam e refletem" (Portas, 1985: 8).

Ao contrário da "renovação" que sempre pressupunha um processo "destrutivo" precedente ao "construtivo" em busca de um "principio de ordem" e de uma "totalidade racional" (Ferrara. 1988), o modelo da revitalizaçāo urbana surgiu 
com um conceito abrangente que incorpora práticas anteriores, mas é mais que a sua simples adição, pois as excede e supera na busca por uma nova vitalidade (econômica, social, cultural e físico-espacial). Esse modelo urbanístico se distancia tanto dos processos traumáticos de renovaçāo, quanto das atitudes exageradamente conservacionistas.

Ao buscar a ampliação da base econômica e social dos centros urbanos, são três os aspectos mais importantes a direcionar o atual paradigma e a ditar a composição de seu modelo urbanístico, refletindo-se diretamente na qualidade físico-ambiental das cidades: maior preocupação pelos contextos existentes e pelo uso de recursos não-renováveis, a ampliação do conceito de patrimônio, que passa a incorporar a "memória coletiva" e nāo apenas os chamados "monumentos" e a busca por maiores processos colaborativos entre os principais grupos políticos e econômicos interessados (governo, comunidades e empresários).

\section{Composição do Modelo de Revitalização de Centros Urbanos}

Modelos são adotados com os mais diferentes "ingredientes": comércio, serviços, habitação, lazer, cultura, turismo, etc. Entretanto, para que os programas de revitalização ganhem momento inicial, geralmente parte-se de um elemento "catalizador" do desenvolvimento. que possa vir a colaborar intensa e continuamente com o processo e a geração desta nova imagem. (Attoe, Logan, 1989; Frieden, Sagalyn, 1989).

Esses catalizadores não podem garantir, por si próprios, o sucesso da revitalização como um todo, mas. sem dúvida, são fatores essenciais para dar partida e, algumas vezes, até mesmo sustentam o processo de revitalização. $\mathrm{Na}$ Europa, Estados Unidos e outros países multiplicam-se programas de revitalização de áreas centrais que se utilizam deste conceito. Os catalizadores podem ser conjuntos histórico-arquitetônicos (French Quarter, Nova Orleans; South Street Seaport. Nova lorque): áreas de importância cívico-simbólica (Pennsy/vania Avenue, Washington), áreas habitacionais (Friedrichstadt, Berlin), novas áreas de pedestres (Curitiba), áreas comerciais e de serviços (Faneuil Mall, Boston; Battery Park-Financial Center, Nova lorque), shoppingcenters (Horton Plaza, San Diego; Bayside Mall, Miami), conjuntos culturais (Times Square, Nova lorque; Candelária, Rio de Janeiro), mercados (Pike Street, Seattle), áreas de lazer e compras (Town Square, Saint Paul; Fisherman's Warf, San Francisco), centros de convenções e aquários (Boston e Baltimore), etc. (Fotos 1 e 2)

Em todos os casos, destaca-se a importância do turismo recreativo e cultural como dinamizador econômico e social. O lazer e a recreação são componentes cada vez mais importantes na vida urbana moderna, que se aproveitam do, e valorizam o, conteúdo histórico-pitoresco das áreas centrais (Appleyard, 1979). Para citar apenas um exemplo, tome-se o caso pioneiro de Boston onde, em 1977. as edificações do antigo mercado - Quincy Market e Faneuil Mall - às margens da área portuária, foram recuperados e transformados num complexo de lojas, mercado, restaurantes e bares, num esforço conjunto entre a prefeitura e a iniciativa privada. No primeiro ano de funcionamento já atraíam dez milhōes de visitantes (total equivalente ao registrado para a Disneylândia no mesmo periodo) e, em meados dos anos 80 , este número atingia 16 milhões/ano, três vezes mais que o total de turistas que entravam no México e no Havaí (estima-se que os verdadeiros turistas no complexo chegavam à metade deste total) (Frieden, Sagalyn. 1989).
Foto 1

O Harborplace, edificaçāo simples com conotaçōes marítimas, abriga conjunto de mercado, lojas, bares e restaurantes no Inner Harbor de Baltimore, um dos mais importantes elementos para revitalização da área central.

Foto: do autor

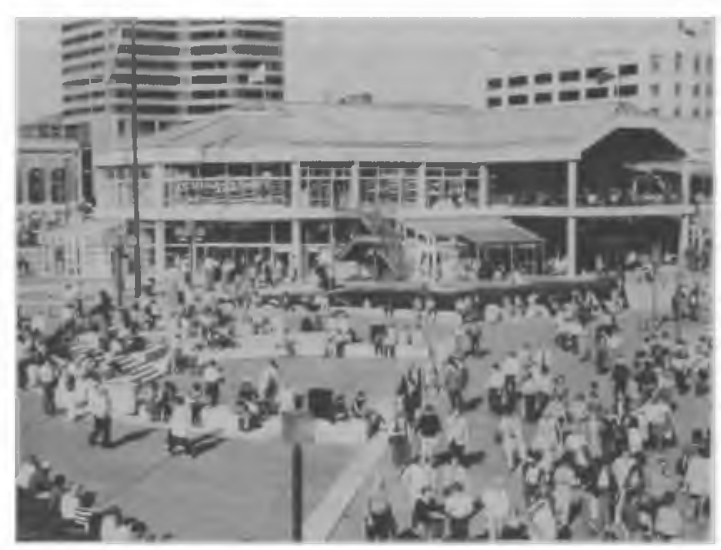

Foto 2

O Aquário Nacional de Baltimore é um importante elemento catalizador que colabora com a revitalização, atraindo milhares de turistas a Baltimore.

Foto: do autor

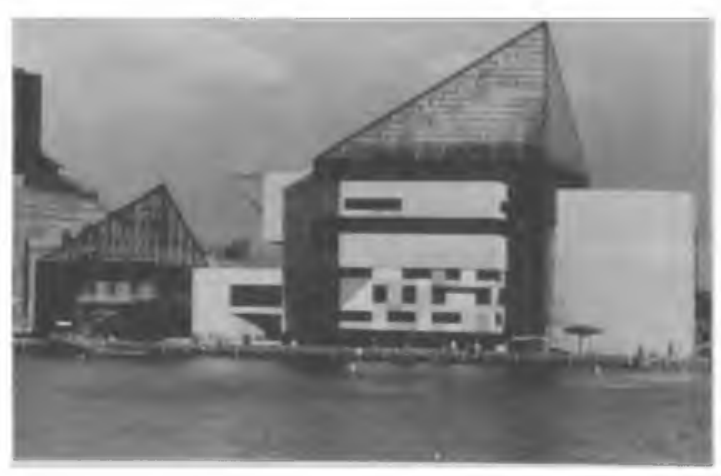

Pós - R. Prog. Pós-Grad. Arquit. Urb. FAUUSP, Sáo Paulo n.4 p. 53-64 dez. 1993 
Foto 3

Recuperação da simbiose entre o rio e a área central de Baltimore, com a promoção do contato físico e visual com a água e diversas atrações turísticas e recreativas.

Foto: do autor

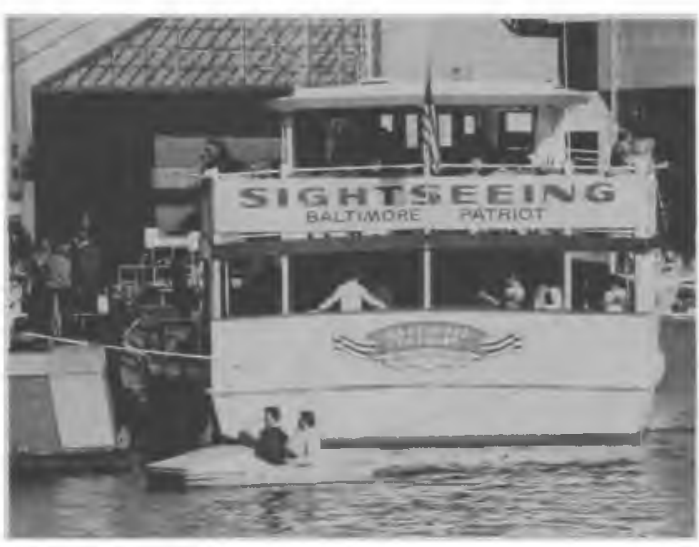

Foto 4

No Corredor Cultural, Rio, um conjunto de fachadas preservadas, hoje já recuperadas, e uma edificação de 1986 construida de acordo com as diretrizes especiais.

\section{Foto: Zeca Linhares}

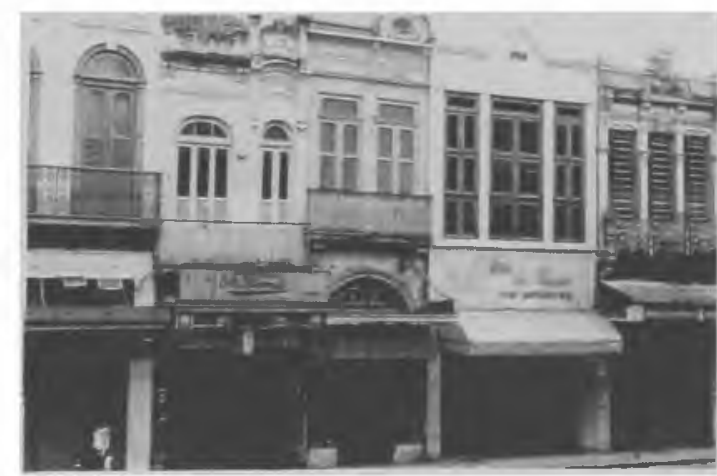

Observe-se que nos casos mais bem sucedidos a presença de corpos d'água e de estruturas históricas são seguidamente tomadas como catalizadores. É particularmente importante o aproveitamento das possibilidades e das conotaçōes simbólicas e lúdicas da água, numa recuperaçāo da simbiose perdida entre a cidade e seu rio, mar ou baía (Wrenn, 1983) (Fig. 3). Este deveria também ser o caso no Rio de Janeiro, particularmente nas áreas central e portuária ao longo da baía, possibilidade que, infelizmente, a prefeitura vem enfrentando de maneira apenas tímida e pouco integral (Del Rio, 1991).

De uma maneira geral, em nosso país, ainda são poucos os programas urbanísticos que perseguem um modelo integral de revitalização, as ações geralmente limitando-se a promover projetos específicos e muitas vezes desligados de um pensamento mais global. Há, entretanto, exceçōes importantes e o quadro parece estar se revertendo com a maioria dos casos se fundamentando na preservaçāo arquitetônica: Corredor Cultural no Rio, Pelourinho em Salvador e Centro de São Luiz. Dentre eles, destacamos a importância do pioneiro Projeto Corredor Cultural, no Rio de Janeiro.

Iniciado em fins de 1979, a partir de modelos europeus, o Corredor Cultural mostra-se como projeto modelar no Brasil. Abrange grande trecho do centro onde são aplicados regulamentos e programas especiais para a preservação de imóveis históricos e construção de novas edificaçōes, atração de novos usos junto com a revitalização/permanência dos antigos e promoção de obras para a recuperação dos espaços públicos. num amplo escopo de revitalização (Pinheiro, 1985). Há sucesso na presenvação da ambiência do conjunto histórico-arquitetônico, na promoção de comércio varejista e de serviços de pequena escala, na animação urbana e na promoção cultural (Fig. 4). Outras áreas não originalmente incluídas no Corredor Cultural têm lucrado com os reflexos, como é o caso da Candelária e seus diversos centros culturais e de exposições já implantados (Casa França-Brasil, Centro Cultural Banco do Brasil, dos Correios, etc.). O centro do Rio vem recuperando sua imagem e seu conteúdo simbólico, atraindo novos usuários, novos usos culturais e comerciais, além de novos investimentos.

Ao definir os modelos de revitalização possíveis, o novo paradigma de desenvolvimento deixa claro um aspecto essencial: a importância da colaboração entre os setores público e privado, num processo de planejamento e implantação que possa envolver grupos representativos da sociedade, diretamente interessados na intervenção e em seus produtos, dividindo benefícios e prejuízos (Frieden, Sagalyn, 1989; Del Rio, 1990). Apenas a participaçāo efetiva e comprometida destes grupos é que pode garantir resultados positivos e de longo prazo.

Enfim, a revitalização de áreas centrais sempre será uma meta difícil principalmente porque luta-se para implementar uma nova imagem para área antes tida como decadente e de má fama, de modo a iniciar um processo progressivo de desenvolvimento social e econômico. Embora muitos destes processos, seja qual for o agente catalizador escolhido, apóiem-se num complexo planejamento comercial, o direcionamento dos investimentos públicos e privados sempre dependerá de uma estratégia intimamente relacionada com a implementação de novas percepçōes e imagens. Ao alterar-se expectativas e valores, os repertórios imagéticos e as comunidades locais sāo fortalecidos, alteram-se comportamentos, atrai-se investimentos, amplia-se o consumo e a oferta de oportunidades, cativa-se novos públicos usuários e garante-se o sucesso financeiro da revitalização. Os objetivos da revitalização devem estar estreitamente relacionados à promoção de uma política consciente de imageabilidade 
urbana. Por isto, talvez a mais fundamental contribuição ao processo de revitalização, de construção da confiança no lugar e, conseqüentemente, da transformaçāo de sua imagem, está nas mãos do poder público. Muito depende da sua postura, da continuidade dos programas, de ações-chaves e de sua capacidade gerencial.

\section{Alguns Cuidados com o Novo Paradigma e seu Modelo de Revitalização}

Portanto, verificamos que o novo paradigma de desenvolvimento e seus modelos urbanísticos prevêem que os interesses do capital, da boa administração pública e das comunidades em geral podem e devem ser compatibilizados. O modelo urbanistico da revitalização, particularmente, possibilita definir objetivos politicamente complementares e açōes integradas. muitas delas a longo prazo.

Atualmente algumas cidades brasileiras têm voltado sua atenção para a importância desse novo paradigma e da exeqüibilidade do seu modelo urbanístico, mas é importante que as possibilidades sejam investigadas criticamente. Embora esteja claro que a revitalizaçāo de áreas centrais nāo pode responder a nenhuma fórmula mágica, podem ser destacadas aqui duas questōes básicas. pertencentes a diferentes esferas e que merecem cuidados especiais.

A primeira questão insere-se na esfera instrumental e refere-se à administração pública e ao planejamento propriamente ditos. Ela é de resolução conceitual simples: muitas de nossas cidades ainda se mostram despreparadas para enfrentar a complexa problemática de suas áreas centrais e para implementar um processo de revitalizaçāo que requer, necessariamente, programas integrados, complementares e metas a longo prazo. Neste sentido, quatro temáticas fundamentais ainda estāo por ser devidamente equacionadas:

- a integração de esforços e objetivos entre os interesses dos setores público, privado e das comunidades diretamente atingidas, compartilhando tanto os lucros quanto os sacrifícios;

- a monitoração e o direcionamento coordenado dos investimentos públicos, através de suas diversas agências, e dos privados, seja de grande ou pequeno porte;

- o comprometimento dos setores envolvidos, principalmente do poder público. com a continuidade de um processo de implementação em que são comuns prazos bastante longos:

- a utilizaçāo de instrumental de planejamento e implementação moderno, flexível e pragmático. que possa privilegiar a exeqüibilıdade, a qualidade do todo e do detalhe.

Embora estas temáticas sejam comuns a qualquer atıvidade de planejamento, que se pretenda séria, revelam-se particularmente estratégicas para o sucesso da revitalização de áreas centrais, especialmente em se tratando de nossas cidades e seus problemáticos sistemas de gerenciamento. Por outro lado, acreditamos que o próprio processo democrático, com a crescente participação de associações representativas da sociedade organizada na gestão urbana, tende a conduzir-nos eventualmente a um correto equacionamento destas temáticas.

A segunda questāo básica se insere na esfera ideológica e do modelo econômico, com rebatimentos bem mais amplos e complexos. Críticas aos modelos existem; nos EUA, por exemplo, o consumismo exacerbado e o pequeno grupo 
(3) Tema de uma pesquisa elaborada no College of Urban Affairs and Planning. University of New Orleans, relatada pessoalmente pelo professor Fritz Wagner em 1988 de grandes empresários investidores neste modelo têm resultado nas mesmas imagens e produtos oferecidos pelas inúmeras intervenções de revitalizaçāo semelhantes, não importa a cidade onde se inserem. O caso lá é de proliferação de shopping-malls, muitas vezes tomado equivocadamente como uma panacéia capitalista de recuperação de áreas centrais deterioradas (Crawford, 1992; Sorkin, 1992). Evidentemente, a maioria dos projetos implantados apenas com esta visāo distorcida e estreita de revitalização renega a essência da vida urbana e gera um ambiente até negativo a ela por seu reducionismo. Essa questão faz parte do caso levantado por Sennet (1990), quando ele argumenta que os ambientes urbanos modernos norte-americanos são sem graça, neutros, destituídos de tudo que possa representar verdadeiros contatos sociais, pois as diferenças acabam sendo tomadas como ameaças, não como estímulos.

Por outro lado, tomando a questāo por seu lado estritamente comercial, a exacerbação de certos aspectos de um modelo pode acabar levando a sua própria destruição, assim como a sua excessiva repetição poderá levar ao risco futuro de esgotar o mercado. Em relaçāo à primeira possibilidade, podemos citar o problema enfrentado pelo French Quarter, a área histórica de Nova Orleans, cujo sucessc está gerando seu abandono pelos moradores originais e sua substituição por usos comerciais, o que pode destruir o seu animado ambiente misto e ameaçar o seu próprio potencial como atração turística ${ }^{3} 0$ mesmo aconteceu na área de entorno do Covent Market, em Londres, e em outras cidades que se utilizam de modelos de revitalização para suas áreas centrais. Para evitar isto, muitos países europeus cuidam em afetar o menos possivel as moradias existentes e promovem seu incremento; dos moradores depende o "ritmo e a essência dos bairros" tornando-se a "palavra de ordem" nas novas políticas para os centros urbanos (Portas, 1985).

Já em relação à segunda possibilidade, o perigo se origina no aumento da importância do marketing de um lugar ou cidade e pelas tendências globais nos padrões de consumo. Além da tendência à homogeinizaçāo dos lugares centrais, as representações e os deslocamentos de diferentes geografias e histórias tornam-se tāo ou mais importantes que a própria realidade (Crawford, 1992; Boyer, 1992; Del Rio, 1992). Exemplo maior é a Disneylândia que. como observou (Sorkin, 1992), espelha perfeitamente a cultura pós-moderna de classe média, que espera uma urbanidade que nāo represente nenhuma ameaça, que possua sensaçōes previsiveis e se apóie em simulacros e no deslocamento das autenticidades para incentivar o fácil consumo de símbolos Na Disneylândia "se produz urbanismo sem se produzir uma cidade... uma hipercidade... de bilhões de cidadãos (todos consumidores), mas nenhum morador... um lugar por onde todos estão apenas passando" (Sorkin. 1992: 231). Essas razōes também estão por detrás das transformaçōes de lugares históricos em objetos de merchandising. como é o caso de modelos populares tipo South Street Seaport (Boyer, 1992). Os especuladores imobiliários já têm trabalhado neste filão, oferecendo empreendimentos com carater histórico "instantâneo" (como é o caso do Battery Park City; Russell, 1992).

Finalmente, as mais profundas transformações que todas as cidades estāo sofrendo e que teremos de enfrentar, refletem-se particularmente nas áreas centrais e eliminam a vida urbana tal como nossa sociedade a conhece há séculos. São elas derivadas de três fatores fundamentais e aparentemente inevitáveis: desintegração das relaçōes humanas com a geografia cultural e física de lugares específicos, a obsessāo por segurança com a proliferação de novos modos de segregaçāo espacial, e o urbano do simulacro, da era da televisāo e da informática (Sorkin. 1992: Virilio. 1993). 
Estão ai expostas as temáticas fundamentais que acreditamos se interpor à verdadeira revitalização das áreas centrais, num processo que possa gerar frutos para a sociedade como um todo e para os grupos sociais que possuem expressāo nas áreas afetadas. Neste sentido, o esforço dentro deste novo paradigma de desenvolvimento, na busca por uma verdadeira urbanidade em seus modelos de revitalizaçāo das áreas centrais, de processos e políticas criativas de desenvolvimento, deve mesclar-se com a luta pela própria democracia. Devemos aprender com as experiências existentes, avaliar seus resultados criticamente e evitar a importaçāo direta de novos modelos e imagens que acabem simplesmente substituindo aqueles gerados por paradigmas anteriores, sempre alheios aos verdadeiros objetivos de nossa socidedade.

\section{Bibliografia}

ABREU, Mauricio. Evoluçảo Urbana do Rio de Janeiro. Rio de Janeiro: Zahar/IPLANRio, 1987

APPLEYARD, Donald (org.). The Conservation of the European City. Cambridge: MIT Press, 1979.

ATTOE, Wayne, LOGAN, Donn. American Urban Architecture: Catalysts in the Design of Cities. University of California Press, 1989.

BARNETT Jonathan. The Elusive City: Five Centuries of Design, Ambition and Miscalculation. New York: Harper \& Row, 1986.

BENCHIMOL, Jaime. A Modernizaçāo do Rio de Janeiro. In: BRENNA, G. (org.) O Rio de Janeiro de Pereira Passos. Rio de Janeiro: Index/PUC, 1985.

BENEVOLO, Leonardo. O Último Capitulo da Arquitetura Moderna. Lisboa: Martins Fontes, 1985.

BLAKE, Peter. Form Follows Fiasco: Why modern Architecture Hasn't Worked Out. Boston: Little Brown. 1974.

BOUCHER, Frédérique. Pour Une Approche Rèaliste des Problemes de Rénovation. In: L'Architecture D'Aujourd'hui, n. 202, 1979.

BOYER, Christine. Cities for Sale: Merchandizing History at South Street Seaport. In: SORKIN, M. (org.) Variations on a Theme Park: The New American City and the End of Public Space. Nova lorque: Noonday. 1992.

CASTELLS, Manuel. El Centro Urbano. In: Problemas de Investigación en Sociologia Urbana. Mexico: Siglo XXI, 1971.

- La Question Urbana. México: Siglo XXI, 1978

CASTEX, J., DEPAULE, J., PANERAI, P Formes Urbaines: de l'lllot a la Barre. Paris: Dunod, 1977

CHOAY, Françoise. The Modern City: Planning in the XIX Century. Nova lorque: Braziller, 1969.

CHIAVARI, Maria P. As Transformações Urbanas do Século XIX. In: BRENNA, G. (org.). $O$ Rio de Janeiro de Pereira Passos. Rio de Janeiro: Index/PUC, 1985.

CRAWFORD, Margaret. The World in a Shopping Center. In: SORKIN, M. (org.) Variations on a Theme Park: The New American City and the End of Public Space. Nova lorque: Noonday, 1992.

DEL RIO. Vicente. Urban Design and Conflicting City Images of Brazil: Rio de Janeiro and Curitiba. In: Cities, v. 9, n. 4. nov. 1992.

Desenho Urbano e Revitalização na Area Portuária do Rio de Janeiro: A Contribuição do Estudo da Percepção Ambiental. São Paulo, 1991. Tese (Doutorado) - Faculdade de Arquitetura e Urbanismo USP, 1991. 
DEL RIO, Vicente. Introdução ao Desenho Urbano no Processo de Planejamento. São Paulo: Pini, 1990.

FERRARA, Lucrécia D'Alessio. Ver a Cidade. Sāo Paulo: Nobel, 1988.

FRAMPTON, Kenneth. Modern Architecture: A Critical History. Londres: Thames \& Hudson, 1981.

FRIEDEN, Bernard, SAGALYN, Lyanne. Downtown, Inc.: How America Rebuilds Cities. Cambridge, MA: M. I. T Press, 1989.

GARCIA, Fernanda Sanchez. Curitiba, Imagem e Mito: Reflexão Acerca da Construção Social de Uma Imagem Hegemônica. Rio de Janeiro, 1993. Dissertação (Mestrado) IPPUR/UFRJ.

PINHEIRO, Augusto Ivan $F$ Corredor Cultural, Um Projeto de Preservaçāo para o Centro do Rio de Janeiro. In: TURKIENICZ, MALTA (org.) Desenho Urbano. São Paulo: PINI, 1985.

PORTAS. Nuno. Notas Sobre a Intervenção na Cidade Existente. In: Revista Sociedade e Território. ก. 2, 1985.

RUSSELL, Frank. Battery Park City: An American Dream of Urbanism. In: Proceedings of the International Symposium on Design Review. Cincinnati: University of Cincinnati, 1992.

SENNET, Richard. The Conscience of the Eye: The Design and Social Life of Cities. New York: Norton, 1990

SORKIN, Michael. See you in Disneyland. In: SORKIN, M. (org.) Variations on a Theme Park: The New American City and the End of Public Space. Nova lorque: Noonday, 1992.

VIRILIO, Paul. O Espaço Crítico. Rio de Janeiro: Editora 34, 1993.

WRENN, D. et al. Urban Waterfront Development. Washington: Urban Land Institute, 1983. 